\title{
Identification of objective (measurable) effects of systematic physical activity of young women participating in Slavica ${ }^{\circledR}$ Dance training
}

Authors' Contribution: A Study Design

B Data Collection

C Statistical Analysis

D Data Interpretation

E Manuscript Preparation

F Literature Search

G Funds Collection

\author{
Justyna Bolek-Adamek ${ }^{1}$ ABDEF , Damian Bojar ${ }^{2}$ c \\ ${ }^{1}$ Gdansk University of Physical Education and Sport, Gdansk, Poland \\ ${ }^{2}$ Gdansk University of Technology, Gdansk, Poland
}

\section{abstract}

Background: Multiple data suggest that cardio workouts improve young women's cardiorespiratory fitness and heart rate. The main goal of this paper is to identify objective (i.e. measurable) effects of systematic physical activity in young women participating in Slavica Dance training.

Material and methods:

Twenty-six young women, aged 20-21 years, constituted one group. Aerobic capacity, anaerobic threshold, heart rate and anaerobic energy metabolism were measured before and after the 8-week training period

Results: Regular participation in the Slavica Dance training resulted in a statistically significant increase in the volume of oxygen delivered and used per minute by the subjects' bodies ( $3.0 \%$ on average). In addition, there was an average relative increase in the anaerobic threshold (AT) of about $2.5 \%$, an average relative decrease in the heart rate $(\mathrm{HR})$ of about $1.0 \%$ and a decrease in the respiratory exchange ratio (RER) during exercise of about $2.6 \%$.

Conclusions: Participating in the Slavica Dance training twice a week for eight weeks increased the performance capacity measured by the maximum oxygen consumption $\mathrm{VO}_{2}$ max. A proper training plan not only helps to achieve the desired results, but also provides an interesting form of physical activity for women of all ages.

Key words: cardio training, Slavica Dance, physical activity, women aged 20-21, dance aerobics.

\section{article details}

Article statistics: Word count: 3,828; Tables: 5; Figures: 4; References: 11

Full-text PDF:

Received: June 2021; Accepted: October 2021; Published: November 2021

http://www.balticsportscience.com

Indexation: Celdes, Clarivate Analytics Emerging Sources Citation Index (ESCl), CNKI Scholar (China National Knowledge Infrastructure), CNPIEC, DOAJ, EBSCO - Central \& Eastern European Academic Source, EBSCO - SPORTDiscus, EBSCO Discovery Service, Google Scholar, Index Copernicus, J-Gate, Naviga (Softweco, Primo Central (ExLibris), ProQuest - Family Health, ProQuest - Health \& Medical Complete, ProQuest - Illustrata: Health Sciences, ProQuest Nursing \& Allied Health Source, Summon (Serials Solutions/ProQuest, TDOne (TDNet), Ulrich's Periodicals Directory/ ulrichsweb, WorldCat (OCLC)

Funding: This research received no specific grant from any funding agency in the public, commercial, or not-for-profit sectors. Authors have declared that no competing interest exists. Justyna Bolek-Adamek; Gdansk University of Physical Education and Sport; email: justyna.bolek@awf.gda.pl

This is an open access article distributed under the terms of the Creative Commons Attribution-Non-Commercial-NoDerivatives 4.0 International (https://creativecommons.org/licenses/by-nc-nd/4.0/), which permits use, distribution, and reproduction in any medium, provided the original work is properly cited, the use is non-commercial and is otherwise in compliance with the license. 


\section{INTRODUCTION}

Physical activity is an intrinsic part of life [1]. If well chosen, physical activity promotes the proper development of the human body. It is a key element of a healthy lifestyle. Regular exercise helps to keep the human body in a good mental and physical condition [1]. Recent years have seen a dynamic increase in interest in healthy lifestyle, regular activity and health care [1]. People are beginning to pay more attention to active recreation, the right amount of exercise during the day and maintaining healthy eating habits. Group exercise classes are seen as an opportunity to increase the frequency of physical activity. The most popular ones are aerobic fitness classes adapted to the participants' abilities, expectations and initial fitness level. The effectiveness of cardio training at different intensities and durations has been tested in various studies $[2,3,4]$.

Active aerobic exercise is a popular form of physical activity among adults. Walking, swimming, equipment-assisted workouts, fitness classes, cycling and running consistently rank among the top fifteen most popular physical activities. They often double up as regular aerobic activity essential for maintaining good health [5]. It is well known that physical activity, among other things, supports the heart function, increases fitness levels, reduces the risk of cardiovascular disease, reduces the risk of obesity, preserves the metabolic function and helps prevent type 2 diabetes $[4,6]$.

Slavica Dance, which is an adaptation of folk dances to modern fitness forms, is an example of group cardio training. For the purposes of the classes, special folk-fitness music is composed. The Slavica Dance fitness programme incorporates steps and figures from the Polish national dances such as mazur, oberek or krakowiak as well as from a number of regional dances from the Kashubian, Rzeszów and Kurpie regions.

Slavica Dance is a workout of progressively increasing intensity followed by a steady power phase. The training load in the initial part of the session is $60 \%$ of HR max (maximum heart rate), whereas the remaining part of the training takes place at an intensity level between 75-85\%, dropping to 50\% of HR max in the cool-down phase. Given the current state of knowledge, it was assumed that the main objective of this study would be to identify any objective (i.e. measurable) changes that may occur in young women's bodies as a result of systematically attending Slavica Dance fitness classes.

The aim of the study was achieved by answering the following research questions:

1. Will Slavica Dance training have a beneficial effect on increasing performance capacity measured by the maximum oxygen consumption threshold $\mathrm{VO}_{2} \max$ (the maximum amount of oxygen absorbed by the body)?

2. Does Slavica Dance training meet the expectations of a cardio workout in terms of reduction of exercise-induced heartbeat frequency?

3. Will systematic participation in Slavica Dance classes result in a reduction of the use of anaerobic energy sources in favour of aerobic metabolism?

\section{MATERIAL AND METHODS}

The study involved 26 young women aged 20-21 years, whose health condition was assessed as very good. The study participants were second- and third-year students at the Occupational Therapy Department of Gdansk University of Physical Education and Sport, Poland (Table 1). 
Table 1. Characteristics of the study participants

\begin{tabular}{cccccc} 
& min & max & average & SD & V\% \\
\hline Age [years] & 20 & 21 & 20.52 & 0.51 & 2.48 \\
Height [cm] & 154 & 180 & 166.07 & 6.78 & 4.08 \\
Weight [kg] & 49.20 & 102.80 & 64.55 & 12.67 & 19.64 \\
BMI [-] & 18.60 & 31.70 & 23.45 & 3.25 & 13.87 \\
\hline
\end{tabular}

\section{AEROBIC CAPACITY TESTS}

To assess aerobic capacity, an exercise test with an increasing load until exhaustion was used according to the Bruce protocol. An ergospirometric exercise test was performed using the Jaeger OxyconPro device. The heart rate was monitored with a Polar H7 transmitter. The test was performed on a mechanical treadmill h/p/cosmos/saturn.

During the exercise test, the load was increased at 3-minute intervals by raising the speed and incline of the treadmill (Table 2).

Table 2. The Bruce protocol treadmill test

\begin{tabular}{ccccc} 
Stage & Speed $[\mathrm{km} / \mathrm{h}]$ & Incline $[\%]$ & Time $[\mathrm{min}]$ & Load $(\mathrm{MET})$ \\
\hline 1 & 2.7 & 10 & 3 & 4 \\
2 & 4.0 & 12 & 3 & 6 \\
3 & 5.4 & 14 & 3 & 9 \\
4 & 6.7 & 16 & 3 & 12 \\
5 & 8.0 & 18 & 3 & 15 \\
6 & 8.8 & 20 & 3 & 17 \\
7 & 9.6 & 22 & 3 & 20
\end{tabular}

1 MET (metabolic equivalent) = the amount of oxygen consumed while sitting at rest; equal to $3.5 \mathrm{ml} 02$ per $\mathrm{kg}$ body weight $\mathrm{x}$ min

Continuous monitoring and recording of indices characterizing respiratory and circulatory function was performed both during exercise and at rest periods. Parameters monitored during the exercise phase included:

- Heart rate (HR) [beats/min],

- Oxygen consumption $\mathrm{VO}_{2}[\mathrm{l} / \mathrm{min}],[\mathrm{ml} / \mathrm{kg} / \mathrm{min}]$,

- Carbon dioxide production $\mathrm{VCO}_{2}[\mathrm{l} / \mathrm{min}],[\mathrm{ml} / \mathrm{kg} / \mathrm{min}]$,

- Minute ventilation VE [1/min],

- Breathing frequency BF [breaths/min],

- Respiratory exchange rate $\mathrm{RER}=\mathrm{VCO}_{2} / \mathrm{VO}_{2}$.

A stress test was performed to determine the maximal aerobic capacity $\left(\mathrm{VO}_{2} \mathrm{max}\right)$ and the anaerobic threshold (AT). The anaerobic threshold was determined by an indirect method using the relative load at which the ventilatory threshold $\left(\mathrm{VT}_{2}\right)$ occurred and when the RER value (rate of utilization of anaerobic energy metabolism during exercise) was one $(R=1)$. To verify the determined AT threshold, respiratory equivalence charts were used: $\mathrm{VE} / \mathrm{VCO}_{2}$, $\mathrm{VE} / \mathrm{VO}_{2}$ and the regression curve of $\mathrm{CO}_{2}$ production $\left(\mathrm{VCO}_{2}\right)$ vs $\mathrm{O}_{2}$ absorption $\left(\mathrm{VO}_{2}\right)$.

\section{ANTHROPOMETRIC MEASUREMENTS}

The following measurements were taken at the beginning of the study, at the end of the research experiment and before each exercise test: body weight and body composition. The components were determined by means of bioelectrical impedance using an InBody 7200 analyser. 


\section{SURVEY}

The study used the author's own survey questionnaire with closed and open-ended questions allowing the respondents either to choose one of the suggested answers or to provide their own one. The survey consisted of nine questions and included a number of questions from the International Physical Activity Questionnaire. The main aim was to verify the lifestyle of the female students under study, especially in the aspect of pro-health behaviour. The survey participants were informed about the requirement to follow the principles of a healthy lifestyle throughout the experiment. The results of the questionnaire are not analysed in this paper.

\section{STATISTICAL ANALYSIS METHODS}

Statistical analysis of the research material was performed using the Statistica 13 software (Statsof, Tulsa, Oklahoma). In order to apply parametric tests of statistical significance, it was necessary to meet the condition of normality of distribution. For this purpose, the ShapiroWilk test was applied. The test results confirmed the normal distribution of the quantitative variables studied; therefore, it was possible to apply the t-test for paired samples, in order to determine the statistical significance of exercise-induced changes.

\section{EESEARCH ARRANGEMENTS}

The first meeting with the study participants outlining the course and scope of the research was held in December 2017. The training process was also discussed and the basic principles of healthy eating were laid out. In the presence of the research organiser, all study participants received a questionnaire to be completed on-site and they signed consent to participate in the study and to process personal data. The study period ran from January to March 2018. All Slavica Dance fitness classes were 55 minutes long and were held twice a week. Fitness and anthropometric examinations were taken twice: at the beginning of the project and again after eight weeks.

\section{Slavica Dance fitness class structure}

Slavica Dance training lasted 55 minutes and was conducted in accordance with fitness methodology. Each individual training session began with a warm-up to activate the upper body parts, in particular: shoulder joints, elbow joints, wrists and correct hand positioning, all at 132 BPM (beats per minute). After the warm-up, the participants moved on to the main part, i.e. learning particular movement patterns. The block (fragmentary) method was applied and exercises were performed at 132 BPM. The method required learning individual elements of the routine, which were then combined into a complete 8-bar music and movement sequence. The same approach was used for each successive sequence, resulting in a final block of $2 \times 32$ bars. Teaching was done symmetrically, by practicing the routine alternately on the right and on the left side. This was followed by gradual teaching of the planned main routine, starting from the basic version - the base, and ending with modification of the combined sequences into coherent arrangements of adapted folk dance steps and fitness steps.

The next part was the grand finale, which complemented or, more precisely, concluded the main part. The grand finale included a few repetitions of the previously learned routine. The last part, the cool down, was aimed at calming the body down. The movements were slower and more fluid. This allowed the participants to calm down faster, and helped tiredness and muscle pain disappear.

The last part of the Slavica Dance class was static stretching, i.e. thorough stretching and relaxation of the musculoskeletal system, lowering the activity of the cardiovascular system. Stretching was mainly performed on those muscles, tendons and joints that were the most active during the main part of the training. With each consecutive week, a transition was 
introduced - the Slavica Dance training consisted of parts, during which the combinations of steps and upper body work varied. The intensity remained the same, but with the introduction of jumps, turns and runs, as well as the involvement of the upper body, the exercises fulfilled the requirement of general development activity and increased the level of energy expenditure during training. The structured, extensive arm work was in harmony with the compilation of choreographic steps.

The 8-week training cycle:

- Weeks 1-4 (two training sessions a week) - choreographic sequences (basic steps), introduction of symmetrical arm movements.

- Weeks 5-8 (two training sessions a week) - more complex choreographic sequences (new figures), introducing asymmetrical arm movements.

\section{RESULTS}

The study group comprised 26 childless young women aged 20-21 with an average BMI of $23.45 \pm 3.25 \mathrm{~kg} / \mathrm{m}^{2}$. Each participant completed a questionnaire describing their current lifestyle habits, including nutrition, and they were informed of the need to maintain these habits for the duration of the study in order to best observe the isolated effect of the proposed Slavica Dance training on the improvement in performance parameters, i.e. AT, $\mathrm{VO}_{2} \max , \mathrm{HR}$ and RER.

The data presented in Table 3 shows the results of the performance tests for the research group.

Table 3. Research group performance test results

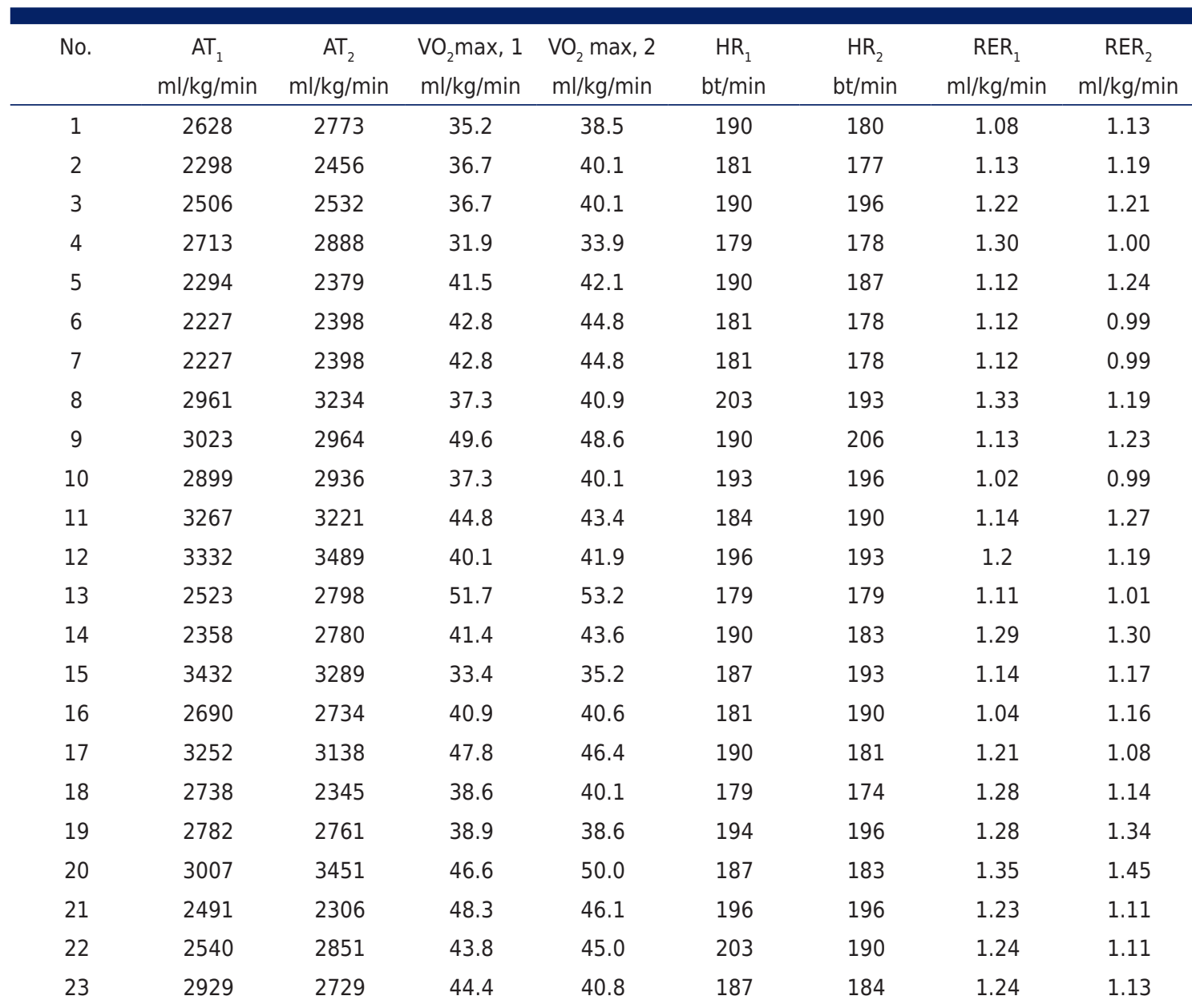




\begin{tabular}{ccccccccc} 
No. & $\begin{array}{c}\mathrm{AT}_{1} \\
\mathrm{ml} / \mathrm{kg} / \mathrm{min}\end{array}$ & $\begin{array}{c}\mathrm{AT}_{2} \\
\mathrm{ml} / \mathrm{kg} / \mathrm{min}\end{array}$ & $\begin{array}{c}\mathrm{VO}_{2} \max , 1 \\
\mathrm{ml} / \mathrm{kg} / \mathrm{min}\end{array}$ & $\begin{array}{c}\mathrm{VO}_{2} \max , 2 \\
\mathrm{ml} / \mathrm{kg} / \mathrm{min}\end{array}$ & $\begin{array}{c}\mathrm{HR}_{1} \\
\mathrm{bt} / \mathrm{min}\end{array}$ & $\begin{array}{c}\mathrm{HR}_{2} \\
\mathrm{bt} / \mathrm{min}\end{array}$ & $\begin{array}{c}\mathrm{RER}_{1} \\
\mathrm{ml} / \mathrm{kg} / \mathrm{min}\end{array}$ & $\begin{array}{c}\mathrm{RER}_{2} \\
\mathrm{ml} / \mathrm{kg} / \mathrm{min}\end{array}$ \\
\hline 24 & 2935 & 3110 & 45.4 & 48.1 & 200 & 187 & 1.11 & 1.14 \\
25 & 2600 & 2767 & 44.7 & 46.2 & 179 & 178 & 1.20 & 1.19 \\
26 & 2286 & 2001 & 42.8 & 44.5 & 200 & 195 & 1.21 & 1.10 \\
\hline Mean & 2728.38 & 2797.23 & 41.75 & 42.98 & 188.85 & 186.96 & 1.19 & 1.16 \\
Sd & 349.6 & 370.2 & 4.9 & 4.3 & 7.5 & 8.0 & 0.1 & 0.1 \\
min & 2227 & 2001 & 31.9 & 33.9 & 179 & 174 & 1.02 & 0.99 \\
max & 3432 & 3489 & 51.7 & 53.2 & 203 & 206 & 1.35 & 1.45 \\
range & 1205 & 1488 & 19.8 & 19.3 & 24 & 32 & 0.33 & 0.46 \\
v\% & $12.8 \%$ & $13.2 \%$ & $11.8 \%$ & $10.1 \%$ & $4.0 \%$ & $4.3 \%$ & $7.3 \%$ & $9.6 \%$ \\
\hline
\end{tabular}

where:

ATi - the i-th measurement of the anaerobic threshold of effort,

$\mathrm{VO}_{2}$ max - the i-th measured volume of oxygen delivered per minute to the body

$\mathrm{HR}_{\mathrm{i}}$ - the i-th heart rate

$\mathrm{RER}_{\mathrm{i}}$ - the i-th measurement of the rate of utilization of anaerobic energy metabolism during exercise.

With $i \in 1,2$, where $i=1$ is the measurement taken before the eight-week training period, and $\mathrm{i}=2$ is the measurement taken upon completion of the eight-week training period. From the data summarised in Table 3 above, it can be seen that there was a change in all the parameters studied as a result of the eight-week training.

With regard to AT, the mean value of the parameter did not change significantly, but it can be seen that the range of variation of this parameter significantly increased, from 1205 to $1488 \mathrm{ml} / \mathrm{kg} / \mathrm{min}$. The small difference between the means in the first and second study can be explained in part by the fact that some of the female subjects studied showed a decrease in the value of the parameter - such a situation applied to 9 of the 26 study participants (in three cases very slightly). Figure 1 below is a graphical representation of the change in the AT parameter in all study participants, in ascending order, according to the results of the first measurement.

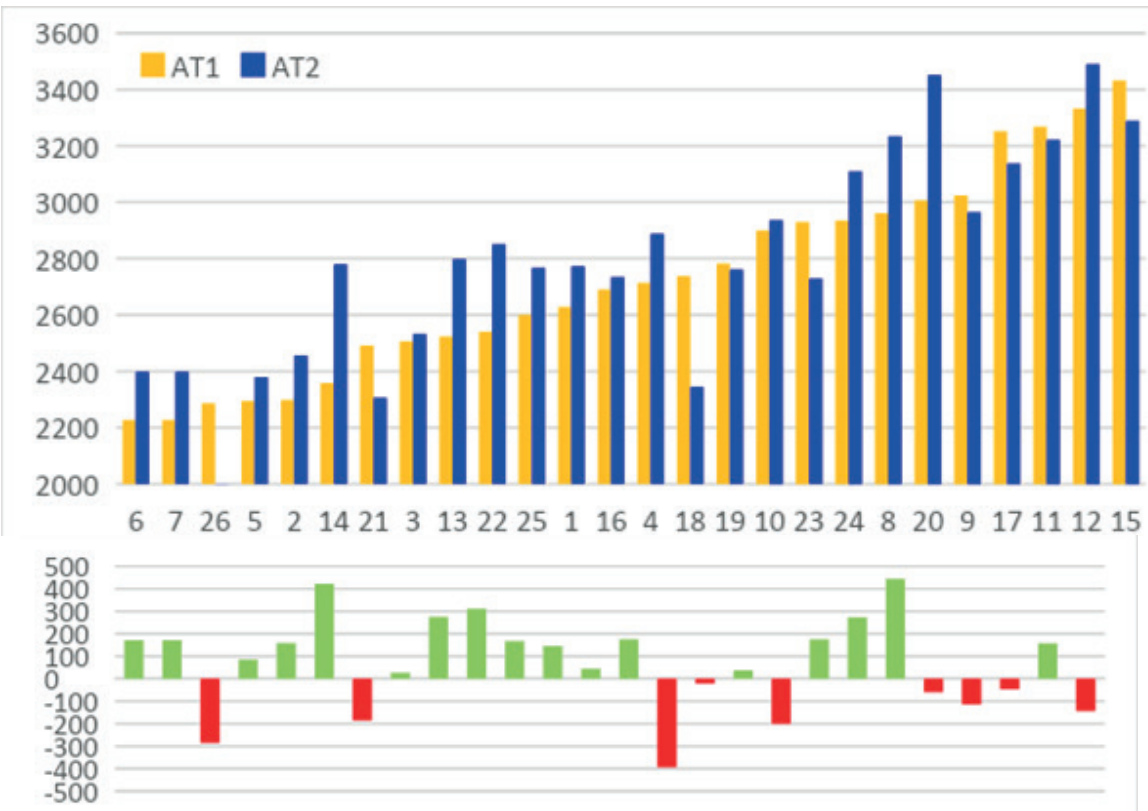

Fig. 1. AT results measured before and after the 8-week training period 
As it can be seen in the graph above, the decrease in the AT threshold was observed both for participants with low and high baseline values of the studied parameter. The most significant decrease was observed in subject '18', who at the first test was above the group average and at the second test had a decrease of $393 \mathrm{ml} / \mathrm{kg} / \mathrm{min}$. A decrease was also noted in three of the four subjects with the highest initial values of the parameter studied. Six female subjects achieved very similar AT values in both studies, with a noticeable increase in the parameter in 14 subjects.

The next parameter assessed was the maximal aerobic capacity $\left(\mathrm{VO}_{2} \mathrm{max}\right)$. In this parameter, the mean value in the first study of $41.75 \mathrm{ml} / \mathrm{kg} / \mathrm{min}$ increased after eight weeks of following the Slavica Dance training by an average of $1.24 \mathrm{ml} / \mathrm{kg} / \mathrm{min}$, with a slightly more pronounced increase in the extreme values. A decrease in $\mathrm{VO}_{2} \max$ was noted for seven out of 26 subjects. Figure 2 below shows the change in $\mathrm{VO}_{2}$ max for all female subjects, in ascending order, according to the results of the first measurement.

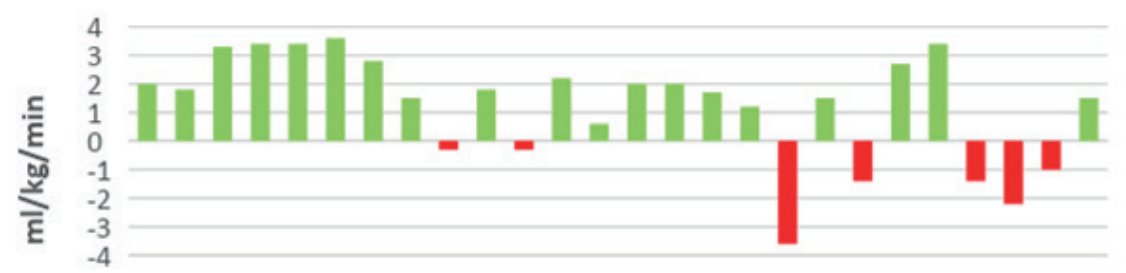

Fig. 2. $\mathrm{VO}_{2}$ max results from the first and second measurement

As can be seen Fig. 2, the greatest training effect in terms of $\mathrm{VO}_{2}$ max was observed in subjects who initially had this parameter in the lower zone of values, while the greatest decreases were observed in five of the nine subjects with the highest initial aerobic threshold. Three subjects achieved very similar $\mathrm{VO}_{2}$ max levels at both testing times.

In terms of exercise-induced heart rate, the group was the most homogeneous, as indicated by the low coefficients of variation in both studies (4.0\% and $4.3 \%$ ). Mean HR changed only very slightly after eight weeks of training, decreasing just by less than two beats per minute. More pronounced changes were observed in the extreme values achieved by the female students tested, resulting in an increase in the variability range from $24 \mathrm{bpm}$ to $32 \mathrm{bpm}$ (see Table 3). There was a decrease in HR in most cases, and only seven study participants had a higher HR level, two of whom noted only a very slight increase. Figure 3 below shows the change in HR, in descending order. 

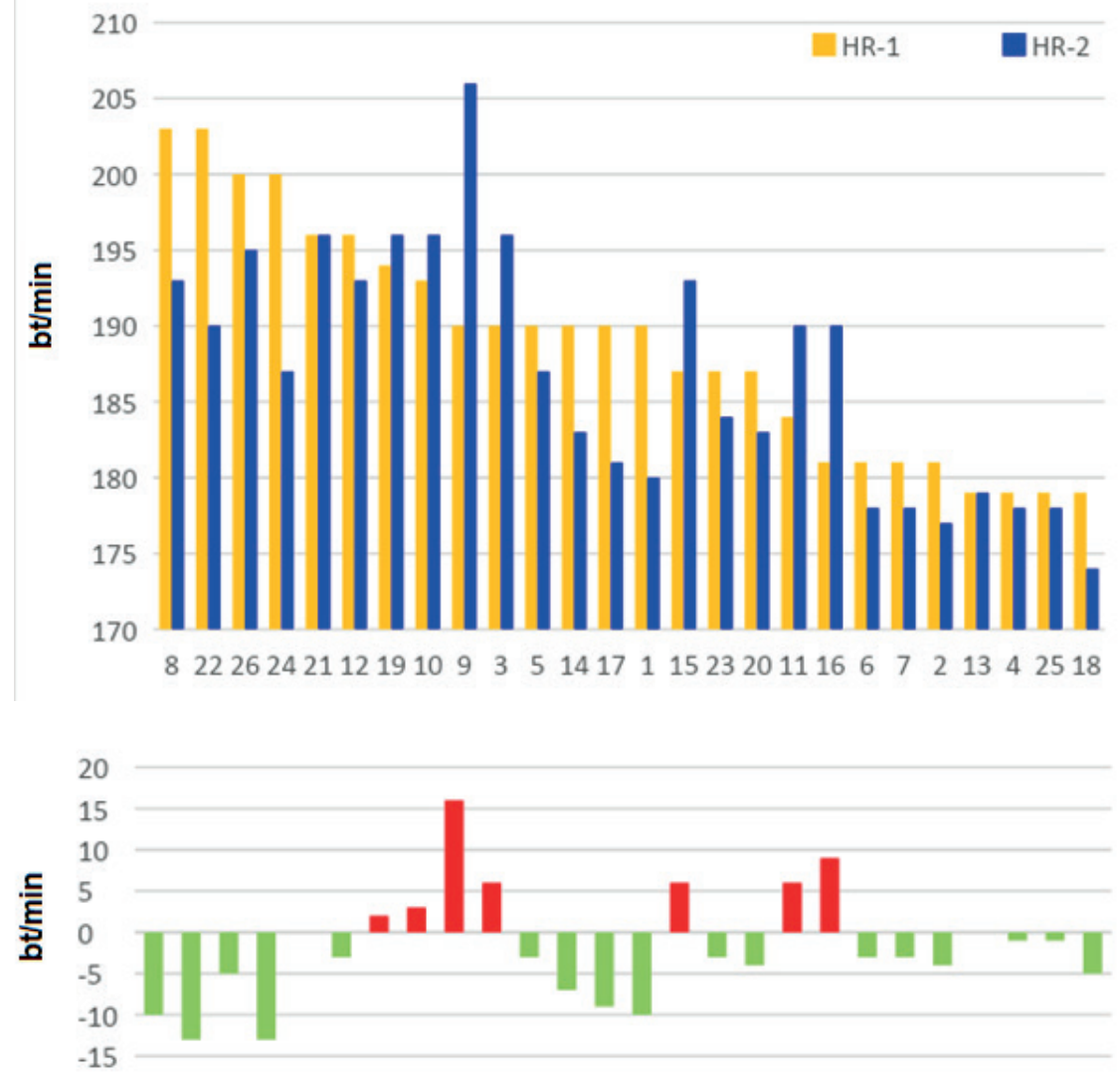

Fig. 3. HR values from the first and second measurement

The Fig. 3 shows that the majority of subjects achieved a beneficial training effect in terms of exercise-induced heart rate. Only five subjects in the mid-range of the initial value (180-190 bpm) were adversely affected, and this group also showed one of the highest decreases $(-10 \mathrm{bpm})$. Two participants were unaffected by the 8-week training period and further six showed only marginal changes. The greatest training effect on HR was observed in the theoretically least fit individuals, who initially showed the highest HR values (187-195 bpm).

Finally, the last studied parameter was the degree of utilisation of anaerobic energy metabolism during exercise, the respiratory exchange rate $\mathrm{RER}=\mathrm{VCO}_{2} / \mathrm{VO}_{2}$. RER values below 1 indicate aerobic metabolism, while values above 1 indicate the use of anaerobic metabolism paths. The analysis showed the smallest changes in absolute values of the parameter, while the averages in both measurements differed by only 0.03 . However, it should be noted that the reference values of RER oscillate around 1.0.

Although the mean RER value changed very little after eight weeks of training, in three cases it decreased to below 1.0 and in further two cases to 1.0, indicating a more efficient use of aerobic energy sources during exercise. The effect of training considerably varied, with almost half of the participants $(n=12)$ achieving the desired effect (a visible reduction in RER), four showing no change and the remainder achieving the opposite effect (an increase in RER). There is hardly any pattern to the changes in RER, as can be seen in Figure 4 below, which graphically presents the change in RER in all the women tested (displayed in descending order of the results of the first test). 


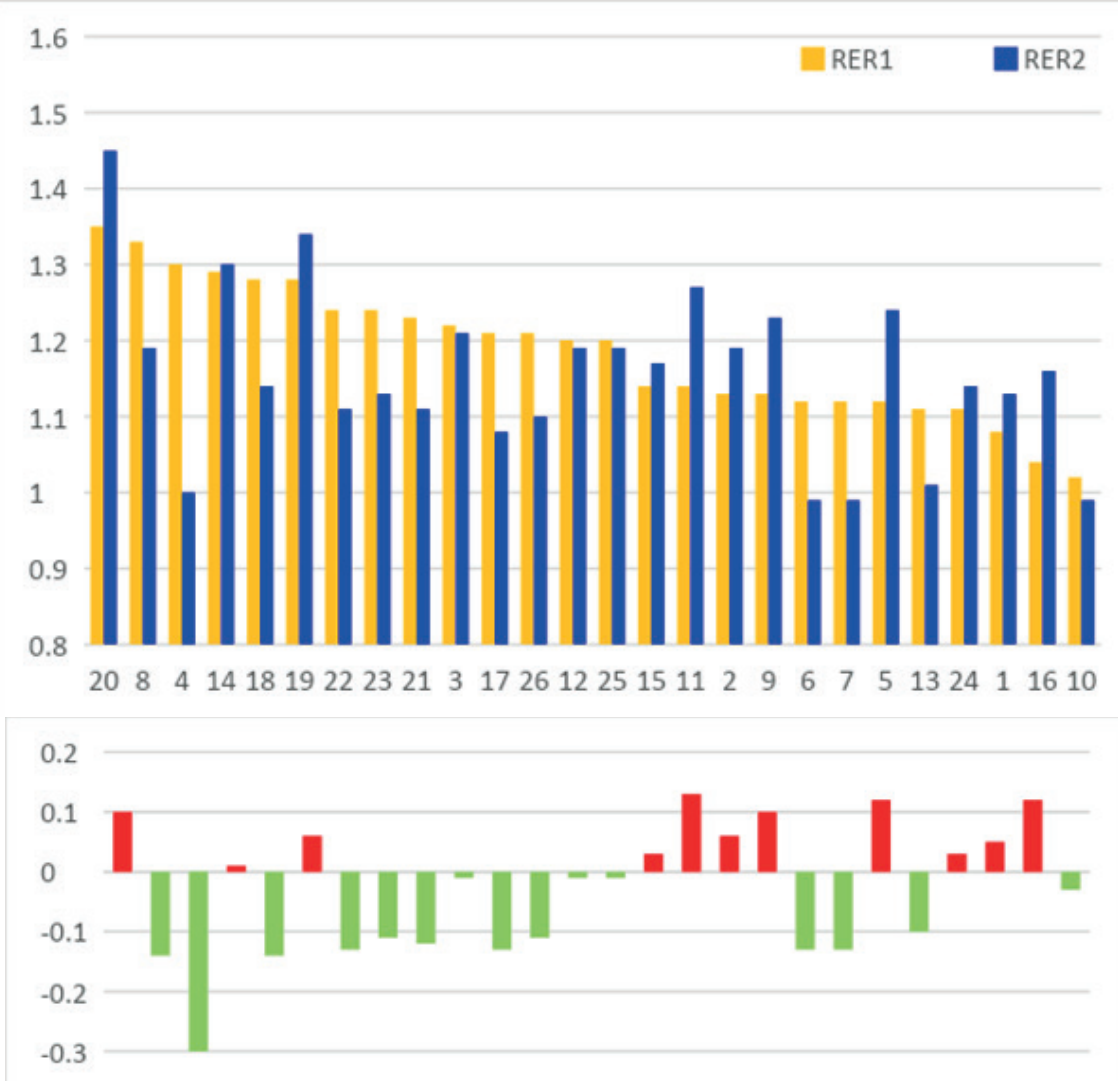

Fig. 4. RER measurement results

Analysis of the distribution of changes in the RER parameter shows that in the second study most of the participants achieved a reading similar to or greater than the first one. Most of the positive effects were observed in subjects who in the first study were located on the left side of the graph, where the weakest results are shown. The group of subjects with lower RER values in the first study, on the other hand, showed most of the weaker effects (increase in RER values).

As the sample size was small, it was not possible to use the chi-square test to assess the normality of the distribution of the measured parameters. The Shapiro-Wilk test was used instead, and the values of the $\mathrm{W}$ and $\mathrm{p}$ parameters are presented in Table 4 below.

Table 4. The Shapiro-Wilk test results

\begin{tabular}{ccc} 
Parameter & W & $\mathrm{p}$ \\
\hline $\mathrm{AT}_{1}$ & 0.951136 & 0.246515 \\
$\mathrm{AT}_{2}$ & 0.973058 & 0.703513 \\
$\mathrm{VO}_{2} \max , 1$ & 0.988737 & 0.989880 \\
$\mathrm{VO}_{2} \max , 2$ & 0.982539 & 0.922687 \\
$\mathrm{HR}_{1}$ & 0.922529 & 0.051553 \\
$\mathrm{HR}_{2}$ & 0.938975 & 0.126942 \\
$\mathrm{RER}_{1}$ & 0.965708 & 0.516044 \\
$\mathrm{RER}_{2}$ & 0.951747 & 0.254717 \\
\hline
\end{tabular}

Taking into account that if the significance coefficient $\mathrm{p}$ is greater than the a ssumed significance level $\alpha(\alpha=0.05)$, it should be concluded that there are no grounds to reject the claim of normality of the distribution. Having proved the normality of the distribution of 
the sample under study, the t-test for paired samples can be applied to observe statistically significant differences. The results of this analysis are presented in Table 5.

Table 5. T-test results for paired samples

\begin{tabular}{cccccc} 
& $\mathrm{x}$ & $\Delta$ & $\mathrm{xj1-xj2}$ & $\mathrm{t}$ & $\mathrm{P}$ \\
\hline $\mathrm{AT}_{1}$ & 2728.385 & 356.5717 & & & \\
$\mathrm{AT}_{2}$ & 2797.231 & 377.4829 & -68.8462 & -1.69078 & 0.103312 \\
$\mathrm{VO}_{2} \max , 1$ & 41.74615 & 5.025712 & & & \\
$\mathrm{VO}_{2}$ max, 2 & 42.98500 & 4.423276 & -1.23885 & -3.30217 & $\mathbf{0 . 0 0 2 8 9 0}$ \\
$\mathrm{HR}_{1}$ & 188.8462 & 7.671726 & & & 0.171112 \\
$\mathrm{HR}_{2}$ & 186.9615 & 8.165688 & 1.884615 & 1.409140 & \\
$\mathrm{RER}_{1}$ & 1.186154 & 0.088276 & & & 0.169529 \\
$\mathrm{RER}_{2}$ & 1.155769 & 0.112718 & 0.030385 & 1.414572 & \\
\hline
\end{tabular}

where:

$x$ - mean value from a given measurement,

$\delta$ - standard deviation,

xj1-xj2 - the difference in diameter of the j-th parameter between the first and the second measurement,

$\mathrm{t}$ - t-Student's statistics,

p - probability value

Assuming a probability value of $\mathrm{p}<0.05$, it should be stated that in the case of the $\mathrm{VO}_{2}$ max parameter statistically significant differences were found. This allows confirming the first hypothesis, namely that the Slavica Dance training resulted in a statistically significant increase (on average by $3.0 \%$ ) in the volume of oxygen supplied and used per minute by the bodies of the study participants. Furthermore, there was an average relative increase in the anaerobic threshold of exercise (AT) of approximately $2.5 \%$, an average relative decrease in heart rate (HR) of approximately $1.0 \%$ and a decrease in the level of utilisation of anaerobic energy metabolism (RER) during exercise of approximately $2.6 \%$.

\section{DISCUSSION}

The starting point of this paper was to determine the changes that may occur as a result of systematically implemented Slavica Dance fitness classes in young women's fitness levels. According to the results, the research objectives were confirmed - the performance capacity measured by the maximal aerobic capacity $\mathrm{VO}_{2}$ max increased during the 8-week research period. A number of additional scientific reports proved that cardio activities had a significant effect on aerobic capacity.

In a study conducted by Jaywant [7], regular aerobic exercise resulted in improved health and endurance. Nowak [8] claims that a modern woman is not only a person who cares only about her health, but also about her appearance. Many women try to delay the ageing process. Maintaining a perfect figure is one of the excellent ways to boost women's selfesteem, make them feel more attractive, and in addition, be fitter.

The common cardio training denominator is the research conducted by Joanna Zapolska [9]. Together with her co-authors, Zapolska studied one of the fitness forms that prevented the incidence of overweight or obesity and supported the process of combating such diseases. According to the author, fitness components include almost all forms of activity that lead to an improvement in health. This also applies, among others, to cardio training [9]. A study conducted by Dorota Kostrzewa Nowak et al. [10] confirms that a 12-week aerobic exercise programme may be sufficient to achieve beneficial effects, such as changes in weight, $\mathrm{BMI}$, skinfold thickness and $\mathrm{VO}_{2}$ max. In addition, they observed changes in body 
composition with a significant decrease in triglyceride and total blood cholesterol levels, as well as HDL and LDL cholesterol levels in the overweight group. The observed effect can be explained by increased energy consumption and reaching the "energy expenditure threshold" during physical exercise.

Significant changes in the body composition after 12 weeks of aerobic exercise were also found by Sanal et al. [11]. The authors compared aerobic exercise (fast outdoor walking and 15 minutes of exercise on a cycle ergometer at an intensity of 50-85\% HRmax) with combined aerobic resistance exercise for the upper and lower body.

In conclusion, it can be said that Slavica Dance training can serve as a versatile solution for improving aerobic capacity, HR, RER and AT. The next research project may be the issue of determining the appropriate training load, which may trigger the loss of body fat and help maintain lean body mass.

\section{CONCLUSIONS}

The results of the study conducted among female students at the Occupational Therapy Faculty of the University of Physical Education and Sport in Gdansk together with the analysis of the relevant literature and the data collected by the author allow formulating several general observations and conclusions:

1. The physical activity of Slavica Dance fitness training repeated twice a week for 8 weeks leads to an increase in performance capacity as measured by the maximal aerobic capacity $\mathrm{VO}_{2} \max$.

2. A proper programme of physical activity not only allows achieving measurable effects, but is also an interesting form of physical activity for women of all ages.

\section{REFERENCES}

[1] Kałwa M. Zmiany nastroju u kobiet po wysiłku fizycznym w zależności od wieku i systematyczności trenowania [Mood changes in women following physical exercise in relation to age and training regularity]. Hygeia Public Health. 2018 53(2):185-192. Polish

[2] Kusnanik NW. The Effect of Zumba and High Impact Aerobic in Reducing Skinfold Thickness. Adv Soc Sci Educ Human Res. 2019;390:165-169.

[3] Prusik K. Kortas J, Prusik K et al. Nordic Walking Training Causes a Decrease in Blood Cholesterol in Elderly Women Supplemented with Vitamin D. Fronti Endocrinol. 2018;9:42. https://doi.org/10.3389/fendo.2018.00042

[4] Barranco-Ruiz Y. Choreographic Group-Based Fitness Classes Improve Cardiometabolic Health-Related Anthropometric Indices and Blood Lipids Profile in Overweight Sedentary Women. Sustainability. 2021;13(2):972 https://doi. org/10.3390/su13020972

[5] Corbin ChB, Welk GJ, Corbin WR, Welk KA,Fitness i wellness. Kondycja, sprawność i zdrowie. Warszawa: Zysk i s-ka, 2007.

[6] Neil-Sztramko SE. Aerobic capacity and upper limb strength are reduced in women diagnosed with breast cancer: A systematic review. J Physiother. 2014;60(4):189-200. https://doi.org/10.1016/j.jphys.2014.09.005

[7] Jaywant PJ. Effect of Aerobic Dance on the Body Fat Distribution and cardiovascular Endurance in Middle Aged Women. J Exerc Sci Physiother. 2013;9(1):6-10. https://doi.org/10.18376//2013/v9i1/67573

[8] Nowak PF.Motywy zdrowotne w hierarchii wartości kobiet ćwiczących w klubach fitness [Health motives in the value hierarchy of women exercising in fitness clubs], Medycyna Ogólna i Nauki o Zdrowiu. 2012;18(4):387-392. Polish.

[9] Zapolska J, Zarębska A, Ostrowska L. Forum Zaburzeń Metabolicznych [Metabolic Disorders Forum]. 2010;1(2):100105. Polish.

[10] Kostrzewa-Nowak D, Nowak R, Jastrzębski Z, et al. Effect of 12-week-long aerobic training programme on body composition, aerobic capacity, complete blood count and blood lipid profile among young women, Biochem Med (Zagreb). 2015;25(1):103-13. http://doi.org/10.11613/BM.2015.013.

[11] Sanal E, Ardic F, Kirac S. Effects of aerobic or combined aerobic resistance exercise on body composition in overweight and obese adults: gender differences. A randomized intervention study. Eur J Phys Rehabil Med 2013;49:1-11. 